\title{
Targeting heterotopic ossification by inhibiting activin receptor-like kinase 2 function (Review)
}

\author{
FULI SHI, JIAYU GAO, JUNRONG ZOU, YING YING and HUI LIN
}

\begin{abstract}
Jiangxi Province Key Laboratory of Tumor Pathogens and Molecular Pathology, Department of Pathophysiology, School of Basic Medicine Sciences, Nanchang University Medical College, Nanchang, Jiangxi 330006, P.R. China
\end{abstract}

Received February 11, 2019; Accepted July 15, 2019

DOI: $10.3892 / \mathrm{mmr} .2019 .10556$

\begin{abstract}
Heterotopic ossification (HO) refers to the appearance of osteoblasts in soft tissues under pathological conditions, such as trauma or infection. HO arises in an unpredictable way without any recognizable initiation. Activin receptor-like kinase-2 (ALK2) is a type I cell surface receptor for bone morphogenetic proteins (BMPs). The dysregulation of ALK2 signaling is associated with a variety of diseases, including cancer and HO. At present, the prevention and treatment of $\mathrm{HO}$ in the clinic predominantly includes nonsteroidal anti-inflammatory drugs (NSAIDs), bisphosphonates and other drug treatments, low-dose local radiation therapy and surgical resection, rehabilitation treatment and physical therapy. However, most of these therapies have adverse effects. These methods do not prevent the occurrence of HO. The pathogenesis of $\mathrm{HO}$ is not being specifically targeted; the current treatment strategies target the symptoms, not the disease. These treatments also cannot solve the fundamental problem of the occurrence of HO. Therefore, scholars have been working to develop targeted therapies based on the pathogenesis of $\mathrm{HO}$. The present review focuses on advances in the understanding of the underlying mechanisms of $\mathrm{HO}$, and possible options for
\end{abstract}

Correspondence to: Dr Hui Lin, Jiangxi Province Key Laboratory of Tumor Pathogens and Molecular Pathology, Department of Pathophysiology, School of Basic Medicine Sciences, Nanchang University Medical College, 461 Bayi Avenue, Nanchang, Jiangxi 330006, P.R. China

E-mail: huilin88@ncu.edu.cn

Abbreviations: ALK2, activin receptor-like kinase 2; $\mathrm{HO}$, heterotopic ossification; BMPs, bone morphogenetic proteins; AHO, acquired heterotopic ossification; HO, genetic heterotopic ossification; FOP, fibrodysplasia ossificans progressive; $\mathrm{POH}$, progressive osseous heteroplasia; MAPK, mitogen-activated protein kinase; FKBP12, 12 kDa FK506 binding protein; MEFs, mouse embryonic fibroblasts; iPSCs, induced pluripotent stem cells; NSAIDs, nonsteroidal anti-inflammatory drugs; AON, antisense oligonucleotides; AMPK, adenosine monophosphate activated protein kinase; $\mathrm{OCN}$, osteocalcin

Key words: ALK2/Activin A receptor type 1, HO, BMPs, therapeutic target the prevention and treatment of $\mathrm{HO}$. In addition, the role of ALK2 in the process of $\mathrm{HO}$ is introduced and the progress made towards the targeted inhibition of ALK2 is discussed. The present study aims to offer a platform for further research on possible targets for the prevention and treatment of HO.

\section{Contents \\ 1. Introduction \\ 2. BMP family and pathway \\ 3. Structure of ALK2 \\ 4. ALK2 signaling pathway in $\mathrm{HO}$ \\ 5. Development of treatments for $\mathrm{HO}$ by targeting ALK2 \\ 6. Conclusion and prospects}

\section{Introduction}

Heterotopic ossification $(\mathrm{HO})$

Definition and classification of $\mathrm{HO}$. HO refers to the appearance of osteoblasts in soft tissue and the formation of bone tissue under pathological conditions, including local and systemic massive ossification (1). In general, $\mathrm{HO}$ can be divided into two categories: Genetic heterotopic ossification (GHO) and acquired heterotopic ossification (AHO). GHO includes fibrodysplasia ossificans progressiva (FOP) (2) and progressive osseous heteroplasia (POH) (3). AHO is characterized by pain and a limited range of motion in the joints. FOP is a rare autosomal-dominant disease characterized by progressive HO. A common mutation $(617 \mathrm{G}>\mathrm{A}$; R206H) of ACVR1/ALK2 causes $>95 \%$ of cases $(4,5)$. Multiple congenital skeletal malformations are associated with FOP, most frequently including an abnormal first toe (6), dysmorphology affecting the digits of the hand (7) and malformations of the cervical spine. $\mathrm{POH}$ is a genetic disease that has a predilection for the skin and subcutis characterized by plaque-like $\mathrm{HO}$, beginning in infancy in the dermis and subsequently developing to involve deep connective tissues, such as the muscles and joints, which sometimes leads to loss of mobility (8). However, a loss-of-function mutation in guanine nucleotide binding protein $\mathrm{G}$ subunit $\alpha$, an imprinted gene, is responsible for POH (9-11). AHO often occurs after severe trauma, such as muscle injury, fracture or dislocation, major joint surgery, myelitis, encephalitis or central nervous 
system damage (3,12-15). The occurrence of $\mathrm{HO}$ can seriously affect quality of life, especially in military service members and veterans. Because these people often suffer combat-related extremity injuries, the global incidence of HO in the military is $63-65 \%$, far higher than the rate of $10-30 \%$ reported globally for ordinary citizens (16). In total, $60 \%$ of AHO occurs in the lower extremities and $\sim 40 \%$ occurs in the upper extremity joints, such as the elbow and shoulder $(15,17)$. Once HO begins to form, it can cause swelling, pain, nerve compression and joint movement disorders around the joints; if it forms in the spine, it leads to limited spinal mobility and spinal cord compression (18). In the early stage of the formation of HO, the patient may experience swelling, pain and elevated skin temperature. The patient cannot undergo rehabilitation training because of fear of pain, which adversely affects the recovery process (19). As the disease progresses, the HO gradually matures, wrapping around or blocking joints, hindering joint activities and reducing the range of motion of the joints, and thereby further affecting the ability of the patient to sit and stand, and hindering weight and gait training. As such, $\mathrm{HO}$ has a great impact on the rehabilitation of patients $(20,21)$.

Formation process of $\mathrm{HO}$. The homeostasis of bone formation is maintained by osteoblasts and osteoclasts, and its formation process is predominantly divided into intramembranous ossification and endochondral ossification (22). Intramembranous ossification begins with mesenchymal differentiation into an embryonic connective tissue membrane, which then forms bone in the membrane, while endochondral ossification mainly refers to the differentiation of mesenchymal precursor cells into chondrocytes $(22,23)$. The development process of HO is similar to the development of normal bone tissue, but it is not strictly in accordance with normal osteogenesis. The ectopic bone not only remodels (just like the normal skeleton) but also expands, with expansion leading to the gradual accumulation of ectopic bone (23). Ectopic bone produced in FOP is formed by endochondral ossification, while intramembranous ossification accounts for $\mathrm{POH}$, while intramembranous ossification and endochondral ossification both contribute to AHO (24). A previous study found that the formation of endochondral-mediated HO involves the inflammation and destruction of connective tissue and the formation of cartilage/bone tissue but not $\mathrm{POH}$ (25). Following a variety of stimuli, such as injury, burns and amputation, a large number of perivascular lymphocytes in the blood leak out of the blood vessel wall during inflammation and move into the early HO area within the muscle and other connective tissues, simultaneously accompanied by damage to the connective tissue structure. Along with lymphocytic infiltration and the destruction of connective tissue structure, an inflammatory reaction, fibrosis and angiogenesis occur, which give rise to the release of osteogenic factors, inducing bone morphogenetic proteins (BMPs) $(22,23)$. These factors induce the formation of mesenchymal cells in the local microenvironment and promote the differentiation of mesenchymal precursor cells into osteoblasts and chondrocytes, eventually forming ectopic bone (Fig. 1) $(25,26)$. However, the cellular origin of the ectopic bone in HO remains a unclear (27) and there have been different hypotheses for the origin of HO progenitor cells, including from muscle (28), vascular endothelia (29), brown fat (30) and the endoneurium (31). In summary, ectopic bone formation requires three conditions: Osteogenic-inducing factors, precursor cells and an appropriate local microenvironment (32).

\section{BMP family and pathway}

BMPs belong to the tumor growth factor (TGF)- $\beta$ superfamily. There are $\sim 20$ types of BMPs, which are divided into four classes in mammals based on sequence and functional similarity: i) BMP2 and 4; ii) BMP5, 6, 7, 8a and 8b; iii) BMP9 and 10; and iv) BMP12, 13 and 14. BMP2, 4, 5, 6, 7 and 9 have a high osteogenic activity $(7,33)$. The BMP signaling pathways are mediated primarily by the formation of heterotetrameric complexes of type I and type II BMP receptors (BMPRs). The TGF- $\beta$ family receptor members are composed of type I and type II receptors, among which there are seven type I BMPRs (ALK1-7) and three type II BMPRs [BMPRII, Activin type II receptor (ActRII) and ActRIIB] (34).

Among all type I receptors, BMPs are more likely to bind to ALK1, 2, 3 and $6(6,35)$. BMP signaling pathways regulate a number of cellular activities, including cell differentiation, proliferation, apoptosis, migration and stem cell self-renewal (36). BMPs have the specific ability to induce cartilage formation and osteogenesis, as well as to promote the formation of endochondral bone (37). Previous clinical and basic medical studies have shown that the BMP pathway plays an important role in $\mathrm{HO}(36,38)$. When a ligand binds to a type II BMPR and phosphorylates it, the type II BMPR phosphorylates and activates the glycine/serine (GS) domain of the type I receptors, which in turn activate Smad-dependent (BMP/Smad) and Smad-independent [BMP/mitogen activated protein kinase (MAPK)] signaling reactions. The BMP/Smad meditated phosphorylation of type I receptors leads to the phosphorylation of $\mathrm{Smad} 1 / 5 / 8$, which subsequently bind to Smad4 and transport it to the nucleus. In the nucleus, Smad1/5/8-Smad4 bind to target genes and upregulate the expression of bone related transcription factors, thereby promoting bone formation. BMP/MAPK mediated phosphorylation of type I receptors activates the MAPK pathways, such as Erk, JNK and p38, thereby regulating transcription factor activity (Fig. 2) $(6,35,36,39)$. As such, both pathways regulate bone metabolism.

\section{Structure of ALK2}

ALK2 belongs to the BMP receptor family (40). In addition, it is a product of the ACVR1 gene, which is located at 2q23-24 (40) (Fig. 3A). The structure of the cytoplasmic domain of ALK2 was resolved in complex with the inhibitors $12 \mathrm{kDa}$ FK506 binding protein (FKBP12) and dorsomorphin (40) which provided a new model for the structure based lead optimization of BMP inhibitors. ALK2 contains the typical ALK receptor domains (Fig. 3B), including a ligand binding extracellular domain, a transmembrane domain, a membrane-associated GS-rich domain and a large kinase domain $(41,42)$. In addition, ALK2 has a typical bilobal kinase architecture with a pattern of specific insertions. These include the L45 loop, the E6 loop, insertions flanking the $\alpha \mathrm{F}$ helix and an insertion in the substrate pocket preceding the $\alpha \mathrm{G}$ helix (41) (Fig. 3C). 


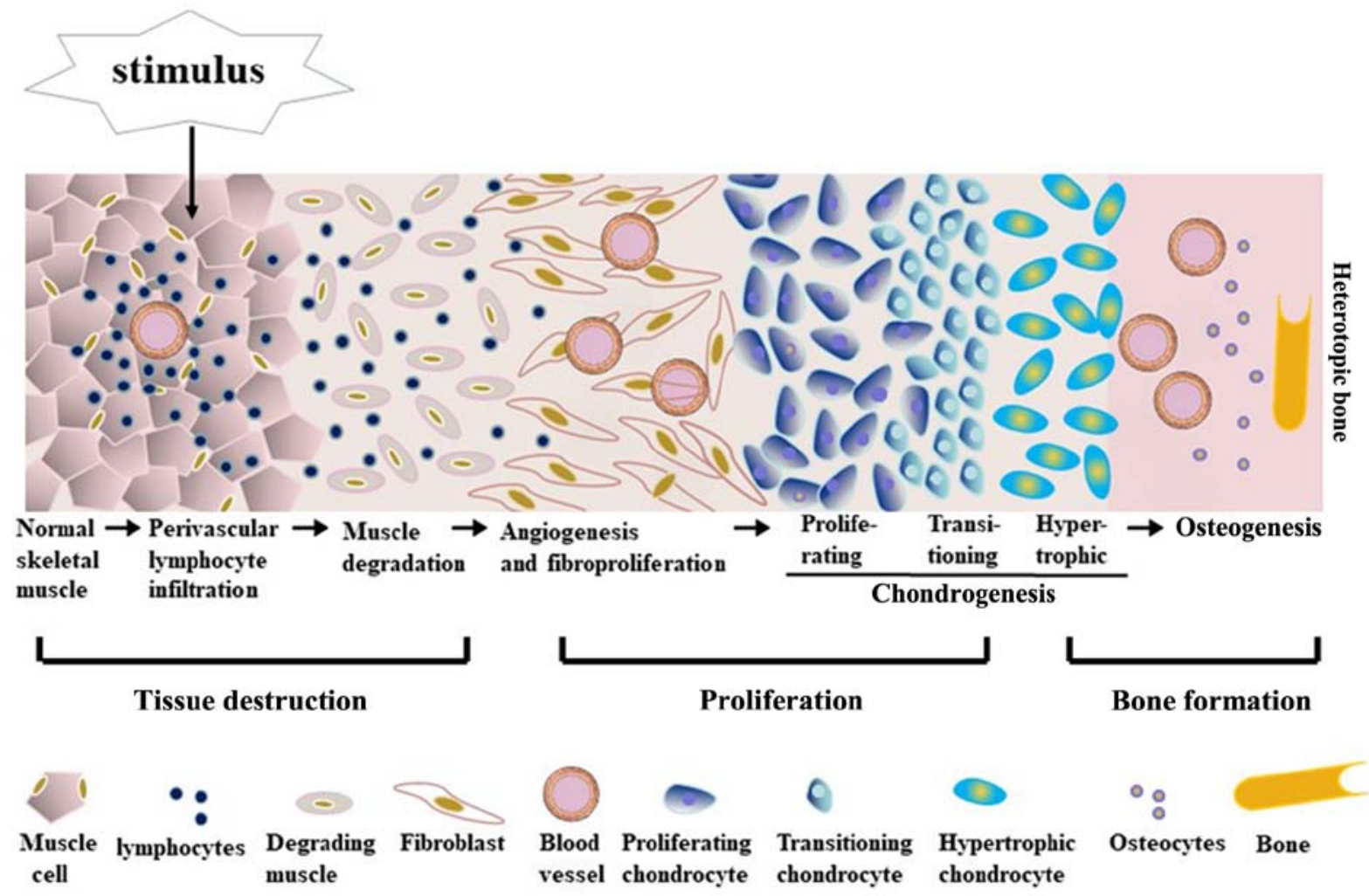

Figure 1. A schematic representation of the stages of HO. The formation of ectopic bone can be divided into three stages: i) Tissue destruction, after a variety of stimuli, a large number of perivascular lymphocytes in the blood leak out of the blood vessel wall during inflammation, and move into the early HO area within the skeletal muscle and connective tissue, this is accompanied by the destruction of the connective tissue structure; ii) proliferation, with the destruction of muscle tissue, the release of inflammatory factors causes fibroplasia and angiogenesis; and iii) bone formation, the second phase promotes the release of some osteogenic-inducing factors that induce mesenchymal precursor cell formation and differentiation into mature cartilage and osteoblasts in a local inflammatory microenvironment. The result of these differentiation processes is the formation of ectopic bone in the area where the tissue has been injured. $\mathrm{HO}$, heterotopic ossification.

Type I receptor kinases are activated by the phosphorylation of the GS domain by type II receptor kinases in the tetramer complex (36). It was shown that the kinase domain has a bifoliate structure, with the GS domain extending from the N-terminal to the helix motif, which can bind to the endogenous inhibitor FKBP12 $(40,42)$. A previous study also showed that FKBP12 prevents entry into the regulatory GS ring and inhibits the $\alpha \mathrm{C}$ movement required for kinase activation (42). In the absence of FKBP12, the inactive conformation in this region is relatively stable, suggesting the conformation and activity of ALK2 are related $(40,42)$.

\section{ALK2 signaling pathway in HO}

ALK2 signaling pathway in GHO. Mutations in ALK2 have not only been associated with cancer, particularly diffuse intrinsic pontine glioma, but have also been linked to HO $(40,41)$.

Type I receptor kinases are typically activated by phosphorylation of the GS domain by type II receptor kinases in the tetramer complex $(40,43)$. However, when ALK2 acquires a functional mutation, ALK2 has reduced binding to the inhibitor FKBP12 and promotes leaky signaling, which continues to activate downstream signals in the absence of the ligand (Fig. 4B) (44). In addition, a loss of function mutation of ALK2 inhibits cartilage formation in mouse embryonic fibroblasts (MEFs) in vitro by inhibiting the phosphorylation of Smad1/5/8, therefore, decreasing ectopic bone formation $(9,15)$; the R206H mutation is not involved in other forms of $\mathrm{HO}$, such as acquired forms and $\mathrm{POH}$. Culbert et al (9) described the function of ALK2 signaling both in vitro and in vivo in the presence of the BMP ligand (Fig. 4D). ALK2R206H/+ MEFs were compared with wild-type MEFs in three-dimensional chondrogenic culture, which were stained with Alcian blue, and it was found that, at the same BMP4 concentration, ALK2R206H/+ cells were more sensitive to BMP4 than wild-type cells. Wild-type or ALK2R206H/+ MEFs with 500 ng BMP4 were injected into the limb muscles of the mice, and it was found that limbs which had been injected with wild-type cells developed no measurable mineralization, while all limbs injected with Alk2R 206H/+ cells developed robust mineralization. In addition, even in the absence of BMP ligands, the ALK2 signaling pathway was continuously activated in ALK2R206H/+ cells. The ALK2R206H gain-of-function mutation enhances both canonical (phospho-Smad1/5/8) and noncanonical BMP signaling responses in the absence of ligands $(9,45)$. However, ALK2R206H/+ mice in which the ALK2R206H mutation was introduced into the second allele closely replicated key features of classic FOP. Chakkalakal et al (46) developed constitutive chimeric ACVR1R206H knock-in mice, as the ALK2R206H mutation causes perinatal lethality. The deformation of the first digits in the posterior limb and ectopic bone formation were observed in the chimeric mice, features also 


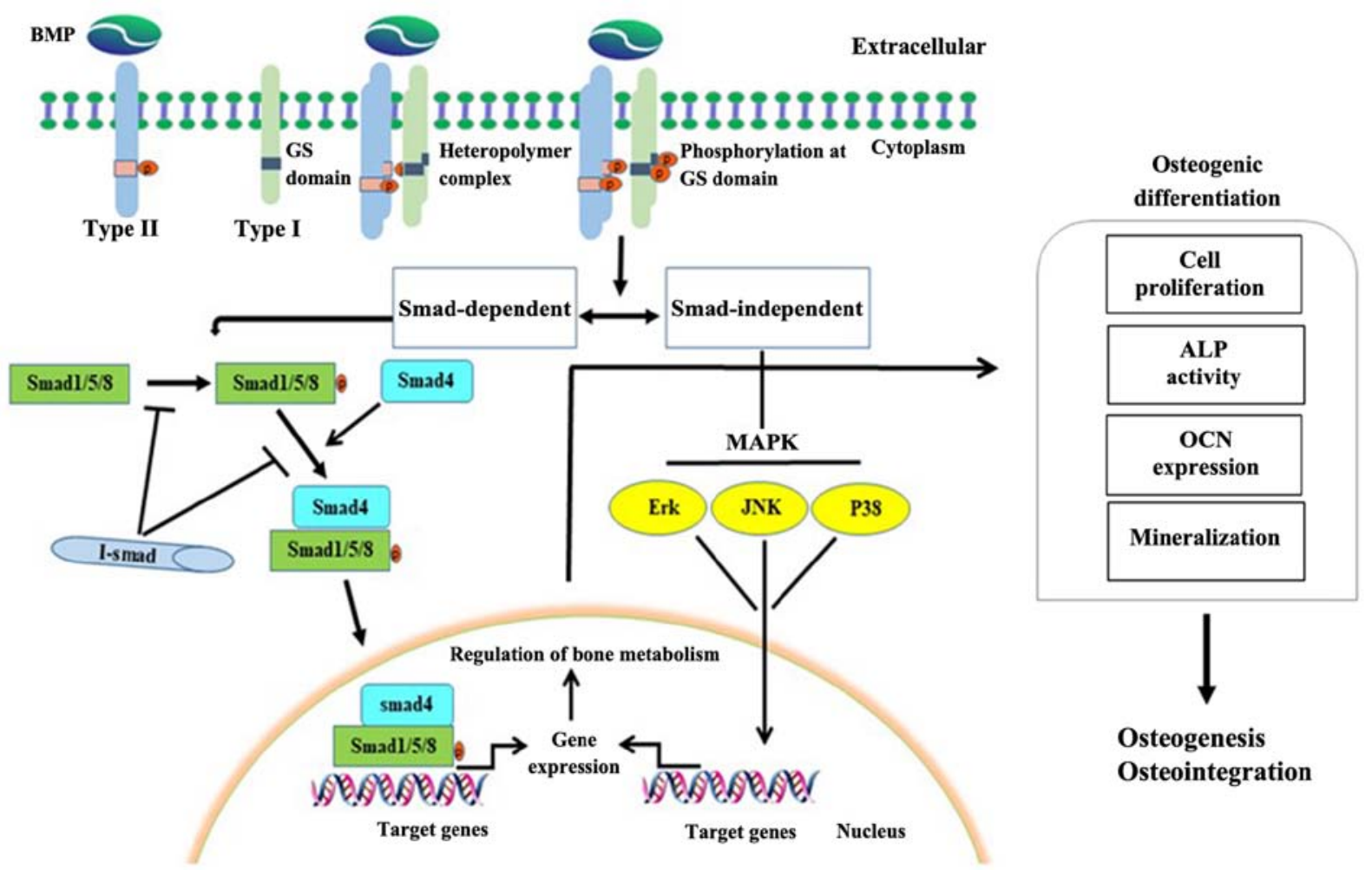

Figure 2. Regulation of the BMP signaling pathway. When BMPs bind to type I (ALK1/ALK2/ALK3/ALK6) and type II (BMP receptors II/Act-II/and Act-IIB) receptors, type II BMP receptors phosphorylate and activate type I receptors through the GS domain, which in turn activates BMP/Smad and BMP/MAPK cascade reactions. The BMP/Smad-mediated phosphorylation of type I receptors leads to the phosphorylation of Smad1/5/8, which binds to Smad4. This complex is transported into the nucleus where it binds to target genes and upregulates the expression of bone related transcription factors, promoting bone formation. The BMP/MAPK-mediated phosphorylation of type I receptors activates MAPK pathways, such as Erk, JNK and P38, thereby regulating transcription factors. Activation of both pathways promotes bone formation. BMP, bone morphogenetic proteins; ALK, activin receptor-like kinase; Act-II, activin type II receptor; GS, glycine/serine; MAPK, mitogen-activated protein kinase; I-Smad, inhibitor Smad; ALP, alkaline phosphatase; OCN, osteocalcin.

A q23-24

Chromosome 2

B

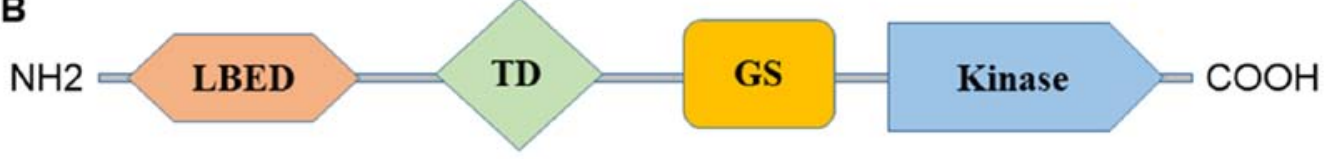

C

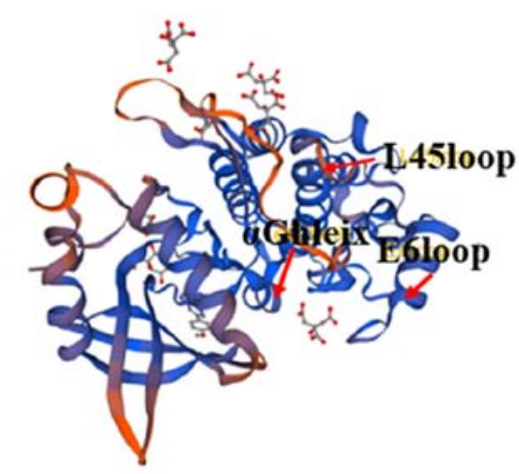

Figure 3. Structure of ALK2. (A) The chromosome location of ALK2. (B) The receptor domains of ALK2. (C) The steric structure of ALK2 protein modeled using the SWISS-MODEL tool. ALK, activin receptor-like kinase; LBED, ligand binding extracellular domain; TD, transmembrane domain; GS, membrane-associated glycine/serine-rich domain.

commonly seen in FOP patients before HO lesions appear; features that are often an important clinical marker of the disease. By 6-8 weeks of age, the mice had extensive HO in skeletal muscle. Moreover, HO developed at injury sites and in 
A

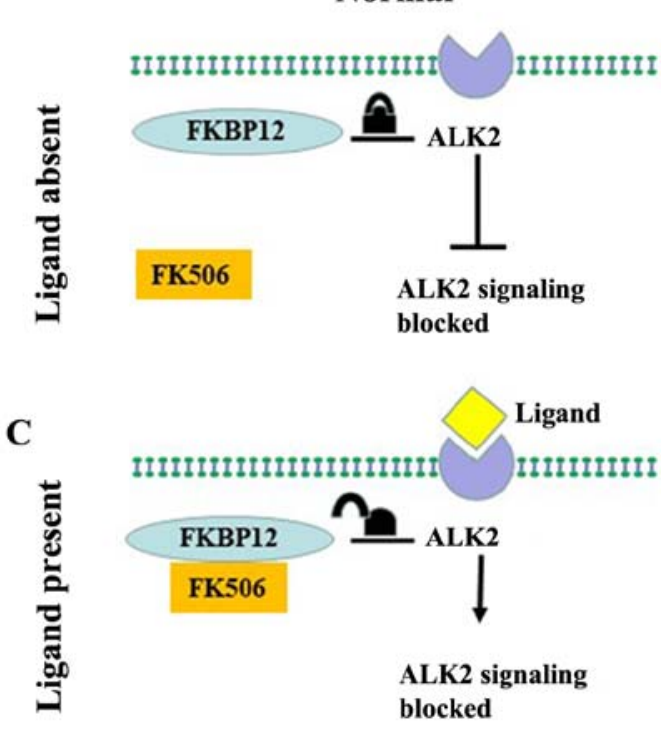

B
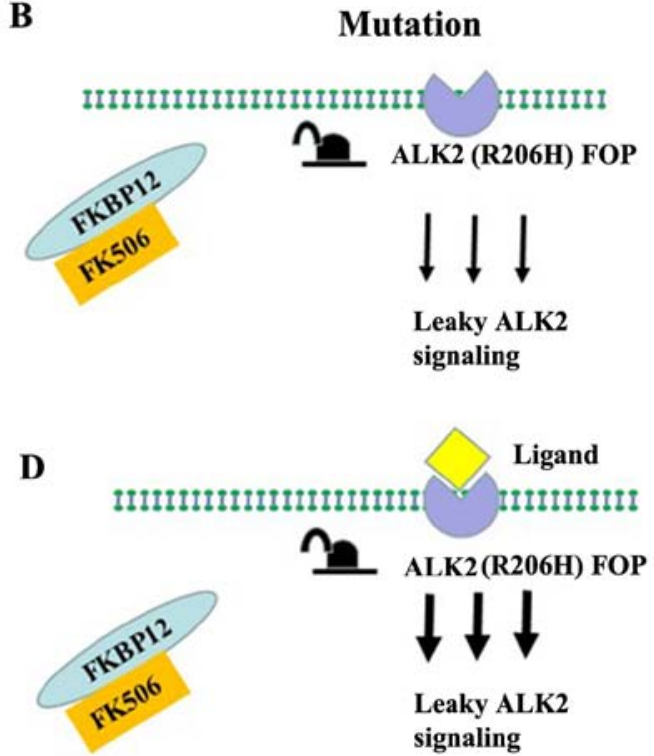

Figure 4. ALK2 signaling in GHO (FOP) and AHO. When ligands are absent (A) FKBP12 forms a complex with ALK2, blocking ALK2 signaling in AHO. (B) In the case of an ALK2 mutation (R206H), FKBP12 no longer interacts with ALK2 but does interact with the immunosuppressant drug FK506, promoting leaky ALK2 signaling in GHO (FOP). When ligands are present (C) FKBP12 no longer interacts with ALK2 in AHO. (D) The presence of a ligand increases the signaling in the presence of an ALK2 mutation in GHO (FOP). GHO, genetic heterotopic ossification; AHO, acquired heterotopic ossification; FOP, fibrodysplasia ossificans progressive; ALK, activin receptor-like kinase; FKBP12, 12 kDa FK506 binding protein.

the surrounding soft tissues. Other genetic models of FOP, that conditionally express ALK2R206H in mice, were developed by Lin et al (42), Hatsell et al (47) and Katagiri (48), and these novel mouse models of FOP carrying the R206H mutation in ALK2 were created using a conditional knock-in genetic technique. Yu et al (49) obtained CAGGS-Cre estrogen receptor mice, which express a tamoxifen-inducible Cre recombinase ubiquitously expressed under the control of the cytomegalovirus immediate-early enhancer and the chicken $\beta$-actin promoter/enhancer. After crossing with Cre driver mice or tamoxifen injection, the ALK2R206H mice developed unprovoked $\mathrm{HO}$ in anatomic sites, including the back, limbs, sternum, ribcage, jaw and hip. In addition, it was noted the mouse model formed $\mathrm{HO}$ in response to skeletal muscle injury, similar to patients with FOP. A related ALK2R206H FOP mouse model was also developed by Lees-Shepard et al (5), in which the expression of ALK2R206H was Cre-dependent.

However, two previous reports demonstrated that the $\mathrm{R} 206 \mathrm{H}$ substitution in ALK2 has novel functions, with the substitution altering activin-specific signaling (47,50). Under normal condition, Activin A usually does not have an osteogenic role. However, in FOP, Activin A leads to activation of Smad1/5/8 phosphorylation via mutant ALK2 signaling, triggering $\mathrm{HO}$ formation. Activin A is secreted by many cell types, among which the cells of the immune system play a basic role in the early phases of FOP lesion formation (47). The binding of activin A to its cognate receptor molecules activates an intracellular signaling cascade mediated by $\operatorname{Smad} 2 / 3$ that regulates the expression of target genes after translocation into the nucleus $(47,51)$. By contrast, the binding of activin A to the ALK2R206H mutant receptor activates downstream signaling through the canonical Smad1/5/8 mediators in several cell types expressing mutated ALK2R206H, such as in induced pluripotent stem cells (iPSCs) derived from patients with
FOP and mouse models $(5,47,50)$. The targeted expression of the disease-causing ALK2 (R206H) allele to fibro/adipogenic progenitors (FAPs) recapitulates all the features of $\mathrm{HO}$ observed in patients with FOP. ALK2R206H-expressing FAPs activate osteogenic signaling in response to activin ligands, but wild-type FAPs do not (5). Lin et al (42), Hatsell et al (47) and Olsen et al (51) reported that activin A can be an antagonist of the BMP/ALK2 signaling pathway by acting as an activator of the ALK2 signaling pathway, with activin A as a precursor signal. For patients with FOP, trauma readily induces new ectopic bone formation, predominantly because activin A activates the mutated ALK2, and the mutation of ALK2 increases sensitivity to activin A (23). These findings have been supported by another previous study (50). Upadhyay et al (23) reported that in the FOP mouse model, both activin A pharmacological and immunological inhibitors could reduce the formation of new ectopic bone in the early stages of ectopic bone formation. It was also reported that, in the case of activin deficiency, even if the Smad1 receptor is continuously activated (promoted by ALK2Q207D), new heterotopic bone cannot be generated $(23,50,51)$. In addition, tissue hypoxia and inflammation promote BMP signaling, chondrogenesis and ectopic bone formation through mutant ALK2 (30,37,52).

ALK2 signaling pathway in AHO. The incidence of acquired forms of $\mathrm{HO}$ may be due to multiple factors, including injury to soft tissues or the central nervous system, burns, and amputations (53). A previous study found that BMP2 is highly expressed in the cerebrospinal fluid of patients with traumatic brain injury (54). The overexpression of various osteogenic transcription factors, including BMP2 and BMP3, has been reported in mouse models of traumatic injury (55). Furthermore, HO can be successfully induced by the injection 
of BMPs into mice, especially BMP2, BMP4 and BMP9 (39). Therefore, BMPs play an important role in the development of HO. However, along with the BMPs, the receptors also play important roles. It has been reported that the expression of ALK is upregulated in an ectopic bone model of spinal cord injury, and that the phosphorylation of Smad and its subsequent translocation into the nucleus are also increased (56). In a tendon burn model, BMP-Smad signaling continued to be activated during the immature phase of ectopic bone formation and fibroproliferation (55). LDN-193189, an inhibitor of BMP type I receptors, effectively reduced the differentiation of mesenchymal stem cells to osteogenic cells in a mouse model of HO following by hip surgery (49). These previous studies have shown that the ALK2 signaling pathway plays an important role in the process of AHO (Fig. 4A and C).

In summary, both AHO and GHO have some commonalities, including the formation of bone tissue in the wrong location and that both are likely regulated by the ALK2 signaling pathway. FOP provides an important model for studying the mechanism of occurrence and development of HO. ALK2 is predominantly expressed in undifferentiated cells, such as mesenchymal stem cells, which have the potential for multifunctional differentiation (9). These undifferentiated cells can differentiate into osteoblast (57). However, the expression of other BMP type I receptors are not necessarily the same. For example, ALK3 is stably expressed throughout the differentiation process, while ALK6 is highly expressed during the differentiation stage compared with the undifferentiated stage (41). The prevention and treatment of diseases should target the underlying causes of the early stages of the disease, therefore, it is imperative to study drug targets for the prevention and treatment of $\mathrm{HO}$.

\section{Development of treatments for HO by targeting ALK2}

Targeted therapies for $\mathrm{HO}$ are being explored, these therapies include the inhibition of BMP receptors (including type I and type II) to block the continued activation of the BMP signaling pathway and thereby inhibit HO (55) (Table I).

The prevention and treatment of $\mathrm{HO}$ in the clinic predominantly includes nonsteroidal anti-inflammatory drugs (NSAIDs), bisphosphonates and other drug treatments, low-dose local radiation therapy and surgical resection, rehabilitation treatment and physical therapy (58). However, most of these therapies have additional clinical benefits. For instance, the use of non-selective NSAIDs, such as naproxen, after hip surgery significantly reduced the incidence of $\mathrm{HO}$, despite the primary use being to relieve inflammation and joint stiffness (59). In addition, indomethacin, which is primarily used to relieve inflammation, is the most effective drug for the inhibition of osteoblast survival in vitro and can promote wound healing in (60). However, NSAIDs may cause gastrointestinal bleeding. Therefore, the topical application of NSAIDs may be a safe and effective method to prevent $\mathrm{HO}$, while avoiding various gastrointestinal complications (61). Radiotherapy may induce malignant tumors and promote the early closure of the epiphysis (62). Bisphosphonates mainly reduce the bone mineralization process by blocking the conversion of amorphous calcium phosphate into hydroxyapatite, however, they do not affect the synthesis of bone matrix. Bisphosphonates delay rather than block the mineralization of $\mathrm{HO}$, therefore, it is easy to resume treatment after stopping administration (63). Surgical resection may cause new ectopic bone formation (64). These methods can only prevent the occurrence of $\mathrm{HO}$ but are not therapies specifically targeted at the pathogenesis of $\mathrm{HO}$, as such, they do not tackle the root cause of the occurrence of HO $(61,62,64,65)$. Therefore, scholars have been working to develop targeted therapies based on the pathogenesis of HO.

Several previous studies have suggested that blocking the ALK2 signaling pathway may inhibit HO $(49,66,67)$. There are three possible mechanisms to inhibit the ALK2 signaling pathway: i) Block the binding of ligands; ii) inhibit the phosphorylation of smad1/5/8 by inhibiting the activity of the ALK2 kinase, and iii) to upregulate the expression of ACVR1, the gene encoding ALK2, at the transcriptional level. Many endogenous protein antagonists that block the binding of ligands to receptors have been discovered, including noggin, follistatin, chordin and gremlin (68). The strategy of targeting ALK2 activity for inhibition has attracted much attention.

\section{Targeting the ALK2 kinase}

Targeting the ALK2 kinase in AHO. An early example of a targeted inhibitor of a BMP type I receptor is dorsomorphin, which inhibits BMP signaling by targeting ALK2, ALK3 and ALK6 (69). However, this inhibitor has poor selectivity and may cause a series of side effects, therefore, optimization is required. At a similar time, the highly selective dorsomorphin derivative LDN-193819 (targeting ALK2 and ALK3) was introduced (70). Yu et al (49) found that HO in a rat model was effectively treated with the high-efficiency ALK2 inhibitor LDN-193819 7 days after the initiation of treatment. At 30 days after the initiation of treatment, 66\% of the rats had effective inhibition of the symptoms of $\mathrm{HO}$ and symptoms in the other rats were also reduced. Furthermore, HO did not recur after the withdrawal of treatment. Further analysis showed that LDN-193819 significantly inhibited the phosphorylation of acetyl-CoA carboxylase, thereby inhibiting the BMP receptor-mediated signal transduction pathway, suggesting that BMP type I receptors can be used as targets for the treatment of HO. Other derivatives have also been developed, including LDN-212854, K02288, DMH-1, ML347 and VU465350 (49,71-74).

Targeting ALK2 kinase in FOP. Among the aforementioned inhibitors, LDN-212854 has a much higher selectivity for ALK2 than for ALK3 or ALK5 compared with other derivatives (75). LDN-212854 showed significant efficacy in the ALK2Q207D transgenic mouse (71) and in a mouse model with the ALK2R206H disease allele knocked in (76), which highly mimics human FOP. Therefore, the interaction of LDN-212854 with ALK2 is suitable for targeting ALK2R206H. The breakthrough in the identification of the structure of this complex provides a template for the future development of targeted ALK2 inhibitors for the treatment of FOP and other related $\mathrm{HO}$ disorders (70).

Targeting ALK2 mRNA. ALK2 is encoded by the gene ACVR1. The aforementioned inhibition of the ALK2 kinase can effectively inhibit $\mathrm{HO}$, therefore, it is important to determine whether directly downregulating the expression of ALK2 
Table I. Inhibition of ALK2.

\begin{tabular}{|c|c|c|c|}
\hline Target & Type & Molecule & Clinical trial phase \\
\hline ALK2 kinase & Small molecule inhibitor $(49,69-74)$ & $\begin{array}{l}\text { Dorsomorphin } \\
\text { LDN-193189 } \\
\text { LDN-212854 } \\
\text { K02288 } \\
\text { DMH-1 } \\
\text { ML347 } \\
\text { VU465350 }\end{array}$ & \\
\hline ALK2 mRNA & $\begin{array}{l}\text { Compound (67) } \\
\text { Gene }(78-85)\end{array}$ & $\begin{array}{l}\text { Dipyridamole } \\
\text { microRNA } \\
\text { AON } \\
\text { ASP-RNAi }\end{array}$ & \\
\hline ALK2 signaling & FDA approved drugs $(88,89)$ & $\begin{array}{l}\text { Fendiline } \\
\text { Perhexiline } \\
\text { Metformin (42) }\end{array}$ & \\
\hline \multirow[t]{2}{*}{ Ligand } & Antibody $(66,91)$ & $\begin{array}{l}\text { Anti-activin-A antibody (REGN2477) } \\
\text { Therapeutic monoclonal antibodies } \\
\text { specific for ALK2 }\end{array}$ & Phase II \\
\hline & Ligand traps $(66,90,92)$ & $\begin{array}{l}\text { sActR-IIA-Fc } \\
\text { sActR-IIB-Fc }\end{array}$ & \\
\hline
\end{tabular}

ALK2, activin receptor-like kinase 2; FDA, Food and Drug Administration; AON, antisense oligonucleotides; ASP-RNAi, allele-specific RNA interference molecules; ActR-II, activin type II receptor.

at the transcriptional level has a similar effect. The $2.9 \mathrm{~kb}$ sequence located at the 5'end of the ACVR1 gene is an active promoter (77). Cappato et al (67) found dipyridamole, which was identified using high-throughput screening, inhibited the production of ectopic bone by downregulating the expression of ACVR1 transcription in a BMP-induced mouse model of HO. Previous studies have also shown that micro (mi)RNAs may regulate the expression of ACVR1 (78-82). Specifically, miRNAs that target the sequence at the 3'untranslated region of the ALK2 gene have been shown to downregulate the expression of ACVR1/ALK2, these miRNAs include miR-365, miR-148b, miR-148a, miR-30-C and miR-130a (78-85).

Another method for downregulating the expression of ACVR1 uses of antisense oligonucleotides (AON), which bind to specific exons of genes in the primary mRNA transcript, thereby preventing splicing and facilitating the skipping of specific exons (86). Shi et al (83) reported the design of AONs to knockdown the expression of mouse ALK2 by means of exon skipping. The ALK2 AON induced exon skipping in cells, which was accompanied by decreased ALK2 mRNA levels and impaired ALK2 signaling in C2C12 cells and endothelial cells. C2C12 cells are mouse myoblasts that are often used to study induced differentiation in vitro, with the cells differentiating into myotubes in vitro under low serum conditions (87). However, these strategies for modulating the expression of ALK2 affect both the wild-type and the mutated allele of the disease-causing gene. From this perspective, RNA interference (RNAi) is a good tool to develop allele-specific therapies for genetic diseases. The design of allele-specific
RNAi molecules to target the expression of mutant ALK2 alleles indicated that the RNAi approach may be successful in FOP $(84,85)$.

Targeting ALK2 signaling. Screening for compounds that can treat HO using drugs already in clinical use will greatly reduce the cost of drug development, and the side effects of these drugs are already clear, therefore, they have high safety profiles. Recently, Yamamoto et al (88) screened drugs that have been approved by the Food and Drug Administration (FDA) using R206H-mutated ALK2-transfected C2C12 cells. It was found that two drugs for preventing angina, fendiline hydrochloride and perhexiline maleate, effectively inhibited the aberrantly activated signaling. Both drugs were also tested in vivo in a mouse model, animals treated with perhexiline maleate or fendiline hydrochloride showed a substantial reduction in the volume of newly formed bone (88). A clinical trial was performed in which perhexiline maleate was given to five patients with FOP to determine the effect of this drug in the control of the disease (89). While the drug was well tolerated, the study did not allow a conclusion to be drawn as the serum levels of alkaline phosphatase (ALP) and bone specific ALP were significantly and synchronously elevated during flare-ups in the patients. Therefore, the trial did not provide good evidence for the clinical utility of perhexiline maleate (89). Dipyridamole, used as a platelet anti-aggregant, was able to downregulate signaling and reduce ectopic bone formation in a BMP-induced mouse model of $\mathrm{HO}$ by decreasing the expression of the ACVR1 gene (67). Moreover, it has been reported that the activation of the 5'AMP-activated protein kinase 
(AMPK) can downregulate ALK2 expression by increasing the interaction of the $\mathrm{E} 3$ protein ubiquitin-protein ligase Smurf1 with Smad6, leading to the inhibition of osteogenic differentiation in MC3T 3 cells and iPSCs derived from patients with FOP (42). Metformin, a first-line drug for the treatment of diabetes, is also a pharmacological activator of AMPK. Our team has constructed a trauma-induced HO mouse model and found that metformin significantly reduced the production of ectopic bone. In addition, our lab also uses other clinically used AMPK activators, including berberine and aspirin, to explore the effects of these drugs on $\mathrm{HO}$ and the underlying mechanisms, and have found them to have significant effects. Thus far, these existing drugs are thought to inhibit the process of ectopic bone formation by inhibiting ALK2/ACVR1; however, there are many other signaling pathways involved in ectopic bone formation. These drugs may also inhibit the formation of ectopic bone through other signaling pathway molecules, and this remains to be explored.

Targeting ligand. Therapeutic monoclonal antibodies specific for ALK2 and activin are under development for in vitro and in vivo studies $(66,90)$. A specific antibody should block the activity of the target protein and preserve the activation of the target protein by its ligands.

Targeting activin A. In several cell types expressing mutated ALK2, the binding of activin A to the R206 $\mathrm{H}$ mutant receptor activates downstream signaling through canonical Smad1/5/8 mediators (5). To research the applicability of these findings in vivo, Hatsell et al (47) developed a physiologically relevant, genetically conditional knock-in mouse model of FOP. Upon pharmacological induction of ALK2R206H expression, mice spontaneously form $\mathrm{HO}$ that completely simulates the phenotype of FOP, including joint function, premature mortality and the development of ectopic bone. The injection of activin A in this mouse model effectively induced ectopic bone formation; moreover, the phenomenon was also observed in wild-type mice. Importantly, the formation of new ectopic bone was prevented by treatment with anti-activin A antibodies (47). These data were consistent with another study (5). The discovery of antibodies to treat $\mathrm{HO}$ is undoubtedly a major breakthrough in the field. A phase II trial has recently been approved and is currently recruiting patients to verify the effects on abnormal bone formation with an anti-activin A antibody (REGN2477) (91).

Targeting ALK2. Mutant ALK2 demonstrates leaky Smad 1/5/8 signaling and ligand hyperresponsiveness, providing a rationale for using antibodies to target ALK2 in the prevention and treatment of FOP. Therapeutic monoclonal antibodies specific for ALK2 are under development (66).

An ALK2-Fc fusion protein, which consists of the human ALK2 extracellular domain (residues 21-123) fused to the Fc portion of the human immunoglobulin gamma 1 constant region (residues 99-330), has been produced as a ligand trap for ALK2 $(66,90)$. A previous in vitro study showed that the ALK2 fusion protein binds to BMP-5/6 with high affinity, had a weak binding capacity for Activin A and inhibited the mutant ALK2-induced phosphorylation of Smad1/5/8. Moreover, the $\mathrm{Fc}$-fusion protein blocked osteoblast differentiation in HUVECs that stably expressed ALK2R206H (92).

\section{Conclusion and prospects}

This review describes $\mathrm{HO}$ and the ALK2 signaling pathways, including the formation of $\mathrm{HO}$, the role of the BMP type I receptor ALK2/ACVR1 in this process, and the structure and regulation of ALK2. Furthermore, the current research into the prevention and treatment of FOP-like $\mathrm{HO}$ was summarized and it was proposed that ALK2 is a potential target for the treatment of $\mathrm{HO}$.

HO undoubtedly severely limits the ability of a patient to move and affects quality of life. In the absence of obvious symptoms and side effects, the ideal treatment is to give the patient a drug on a chronic basis to prevent the acute phase and disease progression. The drug should effectively block the formation of lesions at the very early stages, therefore, strategies that focus on targeting ligand or mutant receptor activity may be more promising than others. However, due to the complexity of the pathogenesis of $\mathrm{HO}$, and in order to improve treatment tolerance and safety, the use of a combination of drugs with different targets and synergistic or additive effects may yield better results, and may reduce the dose of each drug required. Another key aspect is the possibility that a patient may need to stop taking the drug for a variety of reasons. In these cases, it must be ensured that any effects of drug withdrawal will not occur.

Although basic and translational research on $\mathrm{HO}$ has made great progress, some important factors in the pathogenesis of the disease deserve further study, such as the role of the innate and adaptive immune systems, the cross-correlation between different transduction pathways, and the identification of biomarkers suitable for monitoring disease and treatment efficacy. As aforementioned, cells involved in inflammation secrete factors that induce $\mathrm{HO}$, including BMPs. It is important to identify which cells are secreting BMPs and to understand how activin A affects mutated ALK2. These studies will not only help to better understand the disease mechanism, but will also help to provide new drug targets and expand the treatment options available for patients with HO. In addition to FOP, understanding the pathogenesis and determining treatment goals can benefit patients with other more common forms of $\mathrm{HO}$, and those without underlying genetic causes.

Both small molecule inhibitors and FDA-approved drugs for the treatment of other diseases, as well as noncoding RNAs and RNAi, are reported to reduce ectopic bone formation at the cellular level and in animal models. However, all of these strategies are at the stage of basic research, and it will take a time for them to enter clinical use. Therefore, more research to provide an increased number of possibilities for drug developers is required, as is reducing the distance between clinical medicine and basic research. In addition, the dysregulation of the BMP signaling pathway is associated with a variety of diseases, and pharmacological strategies to modulate BMP signaling are an effective strategy to elucidate the specific functions, and multiple biological effects of BMPs. However, the development of small molecule kinase inhibitors faces a huge challenge. The degree of homology between BMP type I receptors is very high, and it is easy to cause off-target effects. With respect to diseases, especially those requiring long-term treatment, off-target effects must be reduced or eliminated. 


\section{Acknowledgements}

Not applicable.

\section{Funding}

The present review was supported in part by grants from the National Natural Science Foundation of China (grant nos. 81272926, 81572753, and 31660332). HL was supported by the Doctoral Scientific Research Foundation from Nanchang University and Young Teachers Research and Development Fund Project from Jiangxi medical college of Nanchang University (grant no. PY201801) and the Natural science Foundation of Jiangxi Province (grant no. 2018BAB215012).

\section{Availability of data and materials}

Not applicable.

\section{Authors' contributions}

FS, JG, JZ, YY and HL were involved in the conception and design of the review. FS and HL drafted the review. FS, JZ, YY, JG and HL revised the manuscript. All authors gave final approval of the manuscript.

\section{Ethics approval and consent to participate}

Not applicable.

\section{Patient consent for publication}

Not applicable.

\section{Competing interests}

The authors declare that they have no competing interests.

\section{References}

1. Edwards DS, Kuhn KM, Potter BK and Forsberg JA: Heterotopic ossification: A review of current understanding, treatment, and future. J Orthop Trauma 30 (Suppl 3): S27-S30, 2016.

2. Hildebrand L, Rossbach B, Kühnen P, Gossen M, Kurtz A, Reinke P, Seemann P and Stachelscheid H: Generation of integration free induced pluripotent stem cells from fibrodysplasia ossificans progressiva (FOP) patients from urine samples. Stem Cell Res 16: 54-58, 2016.

3. Shore EM, Ahn J, Jan de Beur S, Li M, Xu M, Gardner RJ, Zasloff MA, Whyte MP, Levine MA and Kaplan FS: Paternally inherited inactivating mutations of the GNAS1 gene in progressive osseous heteroplasia. N Engl J Med 346: 99-106, 2002.

4. Maruyama R and Yokota T: Morpholino-mediated exon skipping targeting human ACVR1/ALK2 for fibrodysplasia ossificans progressiva. Methods Mol Biol 1828: 497-502, 2018.

5. Lees-Shepard JB, Yamamoto M, Biswas AA, Stoessel SJ, Nicholas SE, Cogswell CA, Devarakonda PM, Schneider MJ Jr, Cummins SM, Legendre NP, et al: Activin-dependent signaling in fibro/adipogenic progenitors causes fibrodysplasia ossificans progressiva. Nat Commun 9: 471, 2018.

6. Wu M, Chen G and Li YP: TGF- $\beta$ and BMP signaling in osteoblast, skeletal development, and bone formation, homeostasis and disease. Bone Res 4: 16009, 2016.
7. Abula K, Muneta T, Miyatake K, Yamada J, Matsukura Y, Inoue M, Sekiya I, Graf D, Economides AN, Rosen V and Tsuji K: Elimination of BMP7 from the developing limb mesenchyme leads to articular cartilage degeneration and synovial inflammation with increased age. FEBS Lett 589: 1240-1248, 2015.

8. Pereda A, Martos-Tello JM, Garin I, Errea-Dorronsoro J and Perez de Nanclares G: Progressive osseous heteroplasia caused by a mosaic GNAS mutation. Clin Endocrinol (Oxf) 88: 993-955, 2018.

9. Culbert AL, Chakkalakal SA, Theosmy EG, Brennan TA, Kaplan FS and Shore EM: Alk2 regulates early chondrogenic fate in fibrodysplasia ossificans progressiva heterotopic endochondral ossification. Stem Cells 32: 1289-300, 2014.

10. Feldman G, Li M, Martin S, Urbanek M, Urtizberea JA, Fardeau M, LeMerrer M, Connor JM, Triffitt J, Smith R, et al: Fibrodysplasia ossificans progressiva, a heritable disorder of severe heterotopic ossification, maps to human chromosome 4q27-31. Am J Hum Genet 66: 128-135, 2000.

11. Regard JB, Malhotra D, Gvozdenovic-Jeremic J, Josey M, Chen M, Weinstein LS, Lu J, Shore EM, Kaplan FS and Yang Y: Activation of Hedgehog signaling by loss of GNAS causes heterotopic ossification. Nat Med 19: 1505-1512, 2013.

12. Forsberg JA, Pepek JM, Wagner S, Wilson K, Flint J, Andersen RC, Tadaki D, Gage FA, Stojadinovic A and Elster EA: Heterotopic ossification in high-energy wartime extremity injuries: Prevalence and risk factors. J Bone Joint Surg Am 91: 1084-1091, 2009.

13. Kaplan FS, Le Merrer M, Glaser DL, Pignolo RJ, Goldsby RE, Kitterman JA, Groppe J and Shore EM: Fibrodysplasia ossificans progressiva. Best Pract Res Clin Rheumatol 22: 191-205, 2008.

14. Kaplan FS, Xu M, Glaser DL, Collins F, Connor M, Kitterman J, Sillence D, Zackai E, Ravitsky V, Zasloff M, et al: Early diagnosis of fibrodysplasia ossificans progressiva. Pediatrics 121: e1295-e1300, 2008.

15. Potter BK, Forsberg JA, Davis TA, Evans KN, Hawksworth JS Tadaki D, Brown TS, Crane NJ, Burns TC, O'Brien FP and Elster EA: Heterotopic ossification following combat-related trauma. J Bone Joint Surg Am 92 (Suppl 2): S74-S89, 2010.

16. Kan L and Kessler JA: Animal models of typical heterotopic ossification. J Biomed Biotechnol 2011: 309287, 2011.

17. Alfieri KA, Forsberg JA and Potter BK: Blast injuries and heterotopic ossification. Bone Joint Res 1: 192-197, 2012.

18. Shehab D, Elgazzar AH and Collier BD: Heterotopic ossification. J Nucl Med 43: 346-353, 2002.

19. Pavey GJ, Polfer EM, Nappo KE, Tintle SM, Forsberg JA and Potter BK: What risk factors predict recurrence of heterotopic ossification after excision in combat-related amputations? Clin Orthop Relat Res 473: 2814-2824, 2015.

20. Gugala Z, Olmsted-Davis EA, Xiong Y, Davis EL and Davis AR: Trauma-induced heterotopic ossification regulates the blood-nerve barrier. Front Neurol 9: 408, 2018.

21. Juarez JK, Wenke JC and Rivera JC: Treatments and preventative measures for trauma-induced heterotopic ossification: A review. Clin Transl Sci 11: 365-370, 2018.

22. Carroll SF, Buckley CT and Kelly DJ: Cyclic tensile strain can play a role in directing both intramembranous and endochondral ossification of mesenchymal stem cells. Front Bioeng Biotechnol 5: 73, 2017.

23. Upadhyay J, Xie L, Huang L, Das N, Stewart RC, Lyon MC, Palmer K, Rajamani S, Graul C, Lobo M, et al: The expansion of heterotopic bone in fibrodysplasia ossificans progressiva is activin A-dependent. J Bone Miner Res 32: 2489-2499, 2017.

24. Xu R, Hu J, Zhou X and Yang Y: Heterotopic ossification: Mechanistic insights and clinical challenges. Bone 109: 134-142, 2018.

25. Lounev VY, Ramachandran R, Wosczyna MN, Yamamoto M, Maidment AD, Shore EM, Glaser DL, Goldhamer DJ and Kaplan FS: Identification of progenitor cells that contribute to heterotopic skeletogenesis. J Bone Joint Surg Am 91: 652-663, 2009.

26. Glaser DL, Economides AN, Wang L, Liu X, Kimble RD, Fandl JP, Wilson JM, Stahl N, Kaplan FS and Shore EM: In vivo somatic cell gene transfer of an engineered Noggin mutein prevents BMP4-induced heterotopic ossification. J Bone Joint Surg Am 85: 2332-2342, 2003.

27. Kan L and Kessler JA: Evaluation of the cellular origins of heterotopic ossification. Orthopedics 37: 329-340, 2014.

28. Ji Y, Christopherson GT, Kluk MW, Amrani O, Jackson WM and Nesti LJ: Heterotopic ossification following musculoskeletal trauma: Modeling stem and progenitor cells in their microenvironment. Adv Exp Med Biol 720: 39-50, 2011. 
29. Medici D, Shore EM, Lounev VY, Kaplan FS, Kalluri R and Olsen BR: Conversion of vascular endothelial cells into multipotent stem-like cells. Nat Med 16: 1400-1406, 2010.

30. Olmsted-Davis E, Gannon FH, Ozen M, Ittmann MM, Gugala Z, Hipp JA, Moran KM, Fouletier-Dilling CM, Schumara-Martin S, Lindsey RW, et al: Hypoxic adipocytes pattern early heterotopic bone formation. Am J Pathol 170: 620-632, 2007.

31. Olmsted-Davis EA, Salisbury EA, Hoang D, Davis EL, Lazard Z, Sonnet C, Davis TA, Forsberg JA and Davis AR: Progenitors in peripheral nerves launch heterotopic ossification. Stem Cells Transl Med 6: 1109-1119, 2017.

32. Gurkan UA, Golden R, Kishore V, Riley CP, Adamec J and Akkus O: Immune and inflammatory pathways are involved in inherent bone marrow ossification. Clin Orthop Relat Res 470: 2528-2540, 2012.

33. Luu HH, Song WX, Luo X, Manning D, Luo J, Deng ZL, Montag AG, Haydon RC and He TC: Distinct roles of bone morphogenetic proteins in osteogenic differentiation of mesenchymal stem cells. J Orthop Res 25: 665-677, 2007.

34. Chen D, Zhao M and Mundy GR: Bone morphogenetic proteins. Growth Factors 22: 233-241, 2004

35. Rahman MS, Akhtar N, Jamil HM, Banik RS and Asaduzzaman SM: TGF- $\beta$ /BMP signaling and other molecular events: Regulation of osteoblastogenesis and bone formation. Bone Res 3: 15005, 015.

36. Sánchez-Duffhues G, Hiepen C, Knaus P and Ten Dijke P: Bone morphogenetic protein signaling in bone homeostasis. Bone 80 : 43-59, 2015.

37. Shore EM and Kaplan FS: Role of altered signal transduction in heterotopic ossification and fibrodysplasia ossificans progressiva. Curr Osteoporos Rep 9: 83-88, 2011.

38. Bouvard B, Masson C, Legrand E and Audran M: Fibrodysplasia ossificans progressiva. A case report and focus on the BMP signaling pathway. Morphologie 100: 250-255, 2016.

39. Kan C, Chen L, Hu Y, Ding N, Lu H, Li Y, Kessler JA and Kan L: Conserved signaling pathways underlying heterotopic ossification. Bone 109: 43-48, 2018.

40. Chaikuad A, Alfano I, Kerr G, Sanvitale CE, Boergermann JH, Triffitt JT, von Delft F, Knapp S, Knaus P and Bullock AN: Structure of the bone morphogenetic protein receptor ALK2 and implications for fibrodysplasia ossificans progressiva. J Biol Chem 287: 36990-36998, 2012.

41. Dudas M, Sridurongrit S, Nagy A, Okazaki K and Kaartinen V: Craniofacial defects in mice lacking BMP type I receptor Alk2 in neural crest cells. Mech Dev 121: 173-182, 2004.

42. Lin H, Ying Y, Wang YY, Wang G, Jiang SS, Huang D, Luo L, Chen YG, Gerstenfeld LC and Luo Z: AMPK downregulates ALK2 via increasing the interaction between Smurf1 and Smad6, leading to inhibition of osteogenic differentiation. Biochim Biophys Acta Mol Cell Res 1864: 2369-2377, 2017.

43. Engers DW, Frist AY, Lindsley CW, Hong CC and Hopkins CR Synthesis and structure-activity relationships of a novel and selective bone morphogenetic protein receptor (BMP) inhibitor derived from the pyrazolo[1.5-a]pyrimidine scaffold of dorsomorphin: The discovery of ML347 as an ALK2 versus ALK3 selective MLPCN probe. Bioorg Med Chem Lett 23 3248-3252, 2013

44. Machiya A, Tsukamoto S, Ohte S, Kuratani M, Fujimoto M Kumagai K, Osawa K, Suda N, Bullock AN and Katagiri T: Effects of FKBP12 and type II BMP receptors on signal transduction by ALK2 activating mutations associated with genetic disorders. Bone 111: 101-108, 2018.

45. van Dinther M, Visser N, de Gorter DJ, Doorn J, Goumans MJ, de Boer J and ten Dijke P: ALK2 R206H mutation linked to fibrodysplasia ossificans progressiva confers constitutive activity to the BMP type I receptor and sensitizes mesenchymal cells to BMP-induced osteoblast differentiation and bone formation. J Bone Miner Res 25: 1208-1215, 2010.

46. Chakkalakal SA, Zhang D, Culbert AL, Convente MR, Caron RJ Wright AC, Maidment AD, Kaplan FS and Shore EM: An Acvr1 R206H knock-in mouse has fibrodysplasia ossificans progressiva. J Bone Miner Res 27: 1746-1756, 2012.

47. Hatsell SJ, Idone V, Wolken DM, Huang L, Kim HJ, Wang L, Wen X, Nannuru KC, Jimenez J, Xie L, et al: ACVR1R206H receptor mutation causes fibrodysplasia ossificans progressiva by imparting responsiveness to activin A. Sci Transl Med 7: 303ra137, 2015.

48. Katagiri T: A door opens for fibrodysplasia ossificans progressiva. Trends Biochem Sci 41: 119-121, 2016.
49. Yu PB, Deng DY, Lai CS, Hong CC, Cuny GD, Bouxsein ML, Hong DW, McManus PM, Katagiri T, Sachidanandan C, et al: BMP type I receptor inhibition reduces heterotopic [corrected] ossification. Nat Med 14: 1363-1369, 2008.

50. Hino K, Ikeya M, Horigome K, Matsumoto Y, Ebise H, Nishio M, Sekiguchi K, Shibata M, Nagata S, Matsuda S and Toguchida J: Neofunction of ACVR1 in fibrodysplasia ossificans progressiva. Proc Natl Acad Sci USA 112: 15438-15443, 2015.

51. Olsen OE, Wader KF, Hella H, Mylin AK, Turesson I, Nesthus I, Waage A, Sundan A and Holien T: Activin A inhibits BMP-signaling by binding ACVR2A and ACVR2B. Cell Commun Signal 13: 27, 2015.

52. Wang H,Lindborg C, Lounev V,Kim JH, McCarrick-Walmsley R, Xu M, Mangiavini L, Groppe JC, Shore EM, Schipani E, et al: Cellular hypoxia promotes heterotopic ossification by amplifying BMP signaling. J Bone Miner Res 31: 1652-1665, 2016.

53. Kent WT, Shelton TJ and Eastman J: Heterotopic ossification around the knee after tibial nailing and ipsilateral antegrade and retrograde femoral nailing in the treatment of floating knee injuries. Int Orthop 42: 1379-1385, 2018.

54. Wang YK, Sun WF, Liu XG, Deng J, Yan BE, Jiang WY and Lin XB: Comparative study of serum levels of BMP-2 and heterotopic ossification in traumatic brain injury and fractures patients. Zhongguo Gu Shang 24: 399-403, 2011 (In Chinese).

55. Peterson JR, De La Rosa S, Eboda O, Cilwa KE, Agarwal S, Buchman SR, Cederna PS, Xi C, Morris MD, Herndon DN, et al: Treatment of heterotopic ossification through remote ATP hydrolysis. Sci Transl Med 6: 255ra132, 2014.

56. Kang H, Dang AB, Joshi SK, Halloran B, Nissenson R, Zhang X, Li J, Kim HT and Liu X: Novel mouse model of spinal cord injury-induced heterotopic ossification. J Rehabil Res Dev 51: 1109-1118, 2014.

57. Lengner CJ, Lepper C, van Wijnen AJ, Stein JL, Stein GS and Lian JB: Primary mouse embryonic fibroblasts: A model of mesenchymal cartilage formation. J Cell Physiol 200: 327-333, 2004.

58. Sun E and Hanyu-Deutmeyer AA: Heterotopic Ossification. StatPearls. Treasure Island (FL): StatPearls Publishing StatPearls Publishing LLC, 2018

59. Beckmann JT, Wylie JD, Potter MQ, Maak TG, Greene TH and Aoki SK: Effect of naproxen prophylaxis on heterotopic ossification following hip arthroscopy: A double-blind randomized placebo-controlled trial. J Bone Joint Surg Am 97: 2032-2037.

60. Rivera JC, Hsu JR, Noel SP, Wenke JC and Rathbone CR: Locally delivered nonsteroidal antiinflammatory drug: A potential option for heterotopic ossification prevention. Clin Trans Sci 8: 591-593, 2015.

61. Rath E, Warschawski Y, Maman E, Dolkart O, Sharfman ZT, Salai M and Amar E: Selective COX-2 inhibitors significantly reduce the occurrence of heterotopic ossification after Hip arthroscopic surgery. Am J Sports Med 44: 677-681, 2016.

62. Beckmann JT, Wylie JD, Kapron AL, Hanson JA, Maak TG and Aoki SK: The effect of NSAID prophylaxis and operative variables on heterotopic ossification after Hip arthroscopy. Am J Sports Med 42: 1359-1364, 2014.

63. Haran M, Bhuta T and Lee B: Pharmacological interventions for treating acute heterotopic ossification. Cochrane Database Syst Rev: CD003321, 2004.

64. Salazar D, Golz A, Israel H and Marra G: Heterotopic ossification of the elbow treated with surgical resection: Risk factors, bony ankylosis, and complications. Clin Orthop Relat Res 472: 2269-2275, 2014.

65. Sheybani A, TenNapel MJ, Lack WD, Clerkin P, Hyer DE, Sun W and Jacobson GM: Risk of radiation-induced malignancy with heterotopic ossification prophylaxis: A case-control analysis. Int J Radiat Oncol Biol Phys 89: 584-589, 2014.

66. Kaplan FS, Pignolo RJ, Al Mukaddam MM and Shore EM: Hard targets for a second skeleton: Therapeutic horizons for fibrodysplasia ossificans progressiva (FOP). Expert Opin Orphan Drugs 5: 291-294, 2017.

67. Cappato S, Tonachini L, Giacopelli F, Tirone M, Galietta LJ, Sormani M, Giovenzana A, Spinelli AE, Canciani B, Brunelli S, et al: High-throughput screening for modulators of ACVR1 transcription: Discovery of potential therapeutics for fibrodysplasia ossificans progressiva. Dis Model Mech 9: 685-696, 2016.

68. Glister C, Regan SL, Samir M and Knight P: Gremlin, Noggin, Chordin and follistatin differentially modulate BMP induced suppression of androgen secretion by bovine ovarian theca cells. J Mol Endocrinol: Oct 1, 2018 (Epub ahead of print). 
69. Yu PB, Hong CC, Sachidanandan C, Babitt JL, Deng DY, Hoyng SA, Lin HY, Bloch KD and Peterson RT: Dorsomorphin inhibits BMP signals required for embryogenesis and iron metabolism. Nat Chem Biol 4: 33-41, 2008.

70. Cuny GD, Yu PB, Laha JK, Xing X, Liu JF, Lai CS, Deng DY, Sachidanandan C, Bloch KD and Peterson RT: Structure-activity relationship study of bone morphogenetic protein (BMP) signaling inhibitors. Bioorg Med Chem Lett 18: 4388-4392, 2008.

71. Mohedas AH, Xing X, Armstrong KA, Bullock AN, Cuny GD and Yu PB: Development of an ALK2-biased BMP type I receptor kinase inhibitor. ACS Chem Biol 8: 1291-1302, 2013.

72. Hao J, Ho JN, Lewis JA, Karim KA, Daniels RN, Gentry PR, Hopkins CR, Lindsley $\mathrm{CW}$ and Hong CC: In vivo structure-activity relationship study of dorsomorphin analogues identifies selective VEGF and BMP inhibitors. ACS Chem Biol 5: 245-253, 2010.

73. Tsugawa D, Oya Y, Masuzaki R, Ray K, Engers DW, Dib M, Do N, Kuramitsu K, Ho K, Frist A, et al: Specific activin receptor-like kinase 3 inhibitors enhance liver regeneration. J Pharmacol Exp Ther 351: 549-558, 2014.

74. Mohedas AH, Wang Y, Sanvitale CE, Canning P, Choi S, Xing X, Bullock AN, Cuny GD and Yu PB: Structure-activity relationship of 3,5-diaryl-2-aminopyridine ALK2 inhibitors reveals unaltered binding affinity for fibrodysplasia ossificans progressiva causing mutants. J Med Chem 57: 7900-7915.

75. Williams E and Bullock AN: Structural basis for the potent and selective binding of LDN-212854 to the BMP receptor kinase ALK2. Bone 109: 251-258, 2018.

76. Dey D, Bagarova J, Hatsell SJ, Armstrong KA, Huang L, Ermann J, Vonner AJ, Shen Y, Mohedas AH, Lee A, et al: Two tissue-resident progenitor lineages drive distinct phenotypes of heterotopic ossification. Sci Transl Med 8: 366ra163, 2016.

77. Giacopelli F, Cappato S, Tonachini L, Mura M, Di Lascio S, Fornasari D, Ravazzolo R and Bocciardi R: Identification and characterization of regulatory elements in the promoter of ACVR1, the gene mutated in Fibrodysplasia Ossificans Progressiva. Orphanet J Rare Dis 8: 145, 2013.

78. Li L, Liu Y, Guo Y, Liu B, Zhao Y, Li P, Song F, Zheng H, Yu J, Song T, et al: Regulatory MiR-148a-ACVR1/BMP circuit defines a cancer stem cell-like aggressive subtype of hepatocellular carcinoma. Hepatology 61: 574-584, 2015.

79. Zumbrennen-Bullough KB, Wu Q, Core AB, Canali S, Chen W, Theurl I, Meynard D and Babitt JL: MicroRNA-130a is up-regulated in mouse liver by iron deficiency and targets the bone morphogenetic protein (BMP) receptor ALK2 to attenuate BMP signaling and hepcidin transcription. J Biol Chem 289: 23796-23808, 2014.

80. Song H, Wang Q, Wen J, Liu S, Gao X, Cheng J and Zhang D: ACVR1, a therapeutic target of fibrodysplasia ossificans progressiva, is negatively regulated by miR-148a. Int J Mol Sci 13 2063-2077, 2012.

81. Mura M, Cappato S, Giacopelli F, Ravazzolo R and Bocciardi R: The role of the 3'UTR region in the regulation of the ACVR1/Alk-2 gene expression. PLoS One 7: e50958, 2012.
82. Karbiener M, Neuhold C, Opriessnig P, Prokesch A, Bogner-Strauss JG and Scheideler M: MicroRNA-30c promotes human adipocyte differentiation and co-represses PAI-1 and ALK2. RNA Biol 8: 850-860, 2011.

83. Shi S, Cai J, de Gorter DJ, Sanchez-Duffhues G, Kemaladewi DU, Hoogaars WM, Aartsma-Rus A, 't Hoen PA and ten Dijke P: Antisense-oligonucleotide mediated exon skipping in activin-receptor-like kinase 2: Inhibiting the receptor that is overactive in fibrodysplasia ossificans progressiva. PLoS One 8: e69096, 2013.

84. Takahashi M,Katagiri T,FuruyaHand HohjohH:Disease-causing allele-specific silencing against the ALK2 mutants, R206H and G356D, in fibrodysplasia ossificans progressiva. Gene Ther 19: 781-785, 2012.

85. Kaplan J, Kaplan FS and Shore EM: Restoration of normal BMP signaling levels and osteogenic differentiation in FOP mesenchymal progenitor cells by mutant allele-specific targeting. Gene Ther 19: 786-790, 2012.

86. Aartsma-Rus A, Fokkema I, Verschuuren J, Ginjaar I, van Deutekom J, van Ommen GJ and den Dunnen JT: Theoretic applicability of antisense-mediated exon skipping for Duchenne muscular dystrophy mutations. Hum Mutat 30: 293-299, 2009.

87. Miki Y, Morioka T, Shioi A, Fujimoto K, Sakura T, Uedono H, Kakutani Y, Ochi A, Mori K, Shoji T, et al: Oncostatin M induces $\mathrm{C} 2 \mathrm{C} 12$ myotube atrophy by modulating muscle differentiation and degradation. Biochem Biophys Res Commun 516: 951-956, 2019.

88. Yamamoto R, Matsushita M, Kitoh H, Masuda A, Ito M, Katagiri T, Kawai T, Ishiguro N and Ohno K: Clinically applicable antianginal agents suppress osteoblastic transformation of myogenic cells and heterotopic ossifications in mice. J Bone Miner Metab 31: 26-33, 2013.

89. Kitoh H, Achiwa M, Kaneko H, Mishima K, Matsushita M, Kadono I, Horowitz JD, Sallustio BC, Ohno K and Ishiguro N: Perhexiline maleate in the treatment of fibrodysplasia ossificans progressiva: An open-labeled clinical trial. Orphanet J Rare Dis 8: 163, 2013.

90. Kaplan FS, Pignolo RJ and Shore EM: From mysteries to medicines: Drug development for fibrodysplasia ossificans progressive. Expert Opin Orphan Drugs 1: 637-649, 2013.

91. Cappato S, Giacopelli F, Ravazzolo R and Bocciardi R: The horizon of a therapy for rare genetic diseases: A 'Druggable' future for fibrodysplasia ossificans progressiva. Int J Mol Sci 19: pii: E989, 2018

92. Pang J, Zuo Y, Chen Y, Song L, Zhu Q, Yu J, Shan C, Cai Z, Hao J, Kaplan FS, et al: ACVR1-Fc suppresses BMP signaling and chondro-osseous differentiation in an in vitro model of Fibrodysplasia ossificans progressiva. Bone 92: 29-36, 2016.

(i) $\odot$ This work is licensed under a Creative Commons Attribution-NonCommercial-NoDerivatives 4.0 International (CC BY-NC-ND 4.0) License. 